\title{
Factors Associated with Problematic Alcohol Consumption among Adults in Putalibazar Municipality of Syangja District, Nepal
}

\author{
Rajeev Nepal $\left(\mathbb{D},{ }^{1}\right.$ Jyoti Priyanka $\left(\mathbb{D},{ }^{1}\right.$ Pradip Chhetri, ${ }^{1}$ Suruchi Godar, ${ }^{2}$ Pratigya Timsina $\left(\mathbb{D},{ }^{3}\right.$ \\ and Saroj Doranga ${ }^{4}{ }^{4}$ \\ ${ }^{1}$ Department of Community Medicine, Universal College of Medical Sciences and Teaching Hospital (UCMS-TH), \\ Bhairahawa, Nepal \\ ${ }^{2}$ BPH Department, Valley College of Technical Sciences, Kathmandu, Nepal \\ ${ }^{3}$ MBS Scholar, Prithvi Narayan Campus, Tribhuvan University, Pokhara, Nepal \\ ${ }^{4}$ ICT Department, Institute of Engineering, Kathmandu, Nepal
}

Correspondence should be addressed to Rajeev Nepal; nepalrajeev11@gmail.com

Received 19 October 2021; Revised 8 January 2022; Accepted 12 January 2022; Published 2 February 2022

Academic Editor: Bayu Begashaw Bekele

Copyright (C) 2022 Rajeev Nepal et al. This is an open access article distributed under the Creative Commons Attribution License, which permits unrestricted use, distribution, and reproduction in any medium, provided the original work is properly cited.

Background. According to the WHO STEPS survey 2013 in Nepal, 17\% of the surveyed population had consumed alcohol within the last 30 days. Alcohol consumption in Nepal is socially and culturally accepted in many ethnic groups. The purpose of this study was to determine various factors associated with problematic alcohol consumption among adults in Putalibazar Municipality of Syangja district. Methods. A community-based cross-sectional study was conducted between September 2020 and January 2021 among 300 adults between ages of 18-64 years in Putalibazar Municipality of Syangja district of Nepal. Using a pretested semistructure questionnaire, a face-to-face interview was performed for collecting the data. An Alcohol Use Disorder Identification Test (AUDIT) developed by the World Health Organization (WHO) was used as a guiding tool to determine the audit-risk level category among adults according to their drinking status. Respondents with scores $0-7$ in AUDIT scores were considered as nonproblematic drinkers, while respondents scoring 8-40 in the AUDIT scores were considered as problematic drinkers. Bivariate and multivariable analysis was performed to find out the association between dependent and independent variables. Variables which were found statistically significant at 95\% CI $(p \leq 0.05)$ during bivariate analysis were further analyzed using the logistic regression model in multivariable analysis to identify determinants associated with problematic alcohol consumption among adults. Results. The mean age of participants was 36.72 years with a \pm 10.81 standard deviation. A total of $56.3 \%$ of adults were problematic drinkers. The multivariable regression analysis model identified adults within the age group of 25-34 years and 35-44 years along with males significantly associated with problematic alcohol consumption. Adults within the age group of 25-34 years and 35-44 years were 7.4 times $(\mathrm{AOR}=7.4, \mathrm{CI}: 1.97-27.60)$ and 5.7 times $(\mathrm{AOR}=5.7, \mathrm{CI}: 1.58-20.56)$ more likely to be problematic drinkers than their counterparts who were from the age group of 55-64 years. Males were 6.9 times more likely to be ( $\mathrm{AOR}=6.9$, CI: 3.35-14.26) problematic drinkers than females. Conclusion. Problematic alcohol consumption among males was common and significantly associated within the age group of 25-34 years and 35-44 years. This study concerns the need for policy makers to launch awareness programs and community-based interventional programs considering identified factors associated with excessive drinking.

\section{Background}

Globally, 3 million deaths worldwide (2.3 million among men and 0.7 million among women) and 132 million DALYs (106 million among men and 26 million among women) were attributable to alcohol, representing $5.3 \%$ of all deaths and 5\% of all DALYs in 2016 [1]. Alcohol consumption is considered as the $7^{\text {th }}$ leading risk factor for both mortality and morbidity [2]. The per capita alcohol consumption in the world's population rose from $5.5 \mathrm{~L}$ of alcohol in 2005 to $6.4 \mathrm{~L}$ in 2010 [2], and it is expected to reach $7.6 \mathrm{~L}$ by 2030 [3]. A systematic analysis of the Global Burden of Disease 2016 
suggested that no amount of alcohol consumption is safe [4]. The International Agency for Research on Cancer (IARC) has determined a causal link between alcohol consumption and cancers, including oral cavity, pharynx, larynx, esophagus, liver, colorectal, and female breast cancer [5].

According to the finding of Nepal's NDHS 2016, almost three out of four women whose husbands often get drunk have experienced spousal physical, sexual, or emotional violence (74\%), compared with less than one in five women (18\%) whose husbands do not drink alcohol [6]. Alcohol use is the eleventh most leading risk factor for Disability Adjusted Life Years (DALYs) in Nepal. According to the WHO STEPS survey 2013 in Nepal; 17\% of the surveyed population (male $28 \%$, female $7.1 \%$ ) had consumed alcohol within the last 30 days; of these, $18.6 \%$ male and $2.9 \%$ female were having binge drinking [7]. Alcohol consumption in Nepal is socially and culturally accepted in many ethnic groups, and the consumption has been increasing over the years across all ethnicities and age groups [8].

While these surveys provide data on the statement of problems and disease burden, they do not assess cultural beliefs and determining factors in the social context where alcohol use behavior occurs. Therefore, this study was mainly conducted to identify various factors associated with problematic alcohol consumption. This study also aims to provide valuable information for other researchers, health service providers, and policy makers in developing interventional programs for the achievement of Goal 3 of Sustainable Development Goals (SDGs) [9] focusing on ensuring good health and wellbeing at all ages by 2030, which significantly strides for good mental health and denotes prevention and treatment of the harmful use of alcohol [10].

\section{Materials and Methods}

2.1. Study Design and Source of Population. A communitybased cross-sectional study was conducted between September 2020 and January 2021 among 300 adults between ages of 18-64 years in Putalibazar Municipality of Syangja district of Nepal. Permanent inhabitants or respondents who stayed more than 5 years in Putalibazar municipality were included in this study. Similarly, respondents who refused to participate in the study, respondents aged $<18$ years and $>64$ years, and those who had severe mental problem were set as exclusion criteria.

\subsection{Sample Size Determination and Sampling Technique.}

The sample size was 300 which was calculated by using formula $n=Z^{2} p q / L^{2}$ [11] with $95 \%$ level of confidence interval, critical value $Z=1.96,5 \%$ margin of error, $7 \%$ nonresponse rate, and the prevalence of alcohol consumption among adults was found to be $23.9 \%$ [12]. Hence, $n=Z^{2} p q / L^{2}=(1.96)^{2} *(0.24) *(0.76) /(0.05)^{2}=280$, by adding $7 \%$ nonresponse rate, the final sample size of the study was 300 . Stratified random sampling was used for the sampling technique. There are 13 wards in the Putalibazar municipality. Each ward was considered as single strata. By using disproportionate stratified sampling techniques, equal 23 samples were taken from wards 1 to 12 , and 24 samples were taken from ward no. 13. Moreover, households were selected from each ward by using the lottery method.

2.3. Setting. Putalibazar municipality is located in Syangja district, Gandaki Province of Nepal. Putalibazar municipality consists of 13 wards [13] and scattered across 147 square kilometers of geographical area [14]. As per 2011 population census, the total population of this municipality was 44,876, and the overall ratio of male to female population in Putalibazar municipality was 0.78 with $43.76 \%$ $(19,638)$ of males and $56.24 \%(25,238)$ of females. In addition, Putalibazar had total 11,882 households (3.78 persons per household) [15], and the overall literacy rate was found to be $76.61 \%$ [14].

2.4. Data Collection Procedures, Validity, and Reliability. Using a pretested semistructure questionnaire, a face-toface interview was performed for collecting the data. A principal investigator self involved in collecting data of the respondents. The questionnaire was translated into Nepali and again retranslated into English language to find misinterpretation, and then correction was made. All the filled questionnaires were reviewed and checked by the principal investigator on a regular basis. In order to maintain the reliability of the questionnaire, the researcher used a reliability analysis test through Cronbach's alpha by taking $8 \%(n=24)$ of the total sample size during pretesting in Galyang municipality which found 0.81 as Cronbach's alpha value that proved that questionnaire was reliable.

2.5. Measure of Practice of Alcohol Consumption. In this study, the practice of alcohol refers to the intake of alcoholic beverages, i.e., beer, wine, spirits (vodka/rum/ whisky), change/jand, and aila by adults in any phase of life. An Alcohol Use Disorder Identification Test (AUDIT) developed by the World Health Organization (WHO) was used as a guiding tool to determine the audit-risk level category (Table 1) which determines Zone I (low-risk drinking), Zone II (higher-risk drinking), Zone III (harmful and hazardous drinking), and Zone IV (possible alcohol dependence) among adults according to their drinking status [16].

In this study, respondents with scores 0-7 in AUDIT scores were considered as nonproblematic drinkers, while respondents scoring 8-40 in the AUDIT scores were considered as problematic drinkers.

2.6. Data Processing and Analysis. Editing, classifying, coding, and entry of data were carried out using Microsoft Excel and exported to Statistical Package for Social Science (SPSS) software version 20 for further analysis. Descriptive and inferential statistics such as mean, median, mode, and standard deviation were applied. The ultimate effect measure (a measure of association) was an odds ratio, and 95\% 
TABle 1: AUDIT-risk level category.

\begin{tabular}{lc}
\hline Audit-risk level & AUDIT score \\
\hline Zone I (low risk drinking) & $0-7$ \\
Zone II (higher risk drinking) & $8-15$ \\
Zone III (harmful and hazardous drinking) & $16-19$ \\
Zone IV (possible alcohol dependence) & $20-40$
\end{tabular}

confidence intervals were used to determine statistical significance. Bivariate and multivariable analysis was performed to find out the association between dependent and independent variables. Variables which were found statistically significant at $95 \% \mathrm{CI}(p \leq 0.05)$ during bivariate analysis were further analyzed using the logistic regression model in multivariable analysis to identify determinants associated with problematic alcohol consumption among adults.

2.7. Ethical Consideration. From the outset of the study, the principles of the Helsinki Declaration were applied, and ethical permission was obtained from the Institutional review committee of UCMS-TH (UCMS/IRC/103/20) and DHO Syangja to conduct this study. Confidentiality of the respondent was maintained. The study was explained to participants, and written informed consent with their signature was obtained for data collection. Withdrawal from the study at any time was accepted, and local language was used during the face-to-face interview.

2.8. Limitation of the Study. This study explored the practice towards alcoholic drinks; the study participants may have been subjected to recall bias. Syangja district constitutes of five municipalities (Nagarpalika) and six rural municipalities (Guanpalika) [17]. As we have conducted this research in Putalibazar municipality, these study findings cannot be generalized to the whole district.

\section{Results}

3.1. Sociodemographic-Related Findings. A total of 300 adults within the age group of 18-64 years were participated in the study (Table 2). The mean age of respondents was found to be 36.72 years with a \pm 10.81 standard deviation. Among study participants, 109 (36.3\%) respondents fell within the age group of 25-34 years, $206(68.7 \%)$ respondents were male, 158 (52.7\%) belonged to Janajati,. 84 (28\%) were involved in business, 190 (63.3\%) were living in a nuclear family, $76(25.3 \%)$ had educational qualification of bachelor degree, 211 (70.3\%) were married, and 120 (40\%) respondent's family monthly income fell within NPR 21,000 to 40,000 .

3.2. Practice-Related Findings. Most 169 (56.3\%) of respondents were problematic drinkers, and rest 131 (43.7\%) respondents were found nonproblematic drinkers on the basis of AUDIT scores (Table 3).

Table 4 describes the distribution of the current drinkers with a reason for the first intake, continuation of alcohol
TABLE 2: Distribution of background-related characteristics of study population $(n=300)$.

\begin{tabular}{lcc}
\hline Variables & No. of respondents $(n)$ & Percentage (\%) \\
\hline Age & & \\
15-24 years & 37 & 12.3 \\
25-34 years & 109 & 36.3 \\
$35-44$ years & 78 & 26 \\
$45-54$ years & 57 & 19 \\
$54-64$ years & 19 & 6.3
\end{tabular}

Mean age 36.72 years, SD \pm 10.81, Max 64 Years, and Min 18 Years

\begin{tabular}{lcc}
\hline Gender & & \\
Male & 206 & 68.7 \\
Female & 94 & 31.3 \\
\hline Ethnicity & 158 & \\
Janajati & 82 & 52.7 \\
Brahmin & 50 & 27.3 \\
Dalit & 10 & 16.7 \\
Kshetri & & 3.3 \\
\hline Occupation & 84 & \\
Business & 59 & 28 \\
Private job & 46 & 19.7 \\
Student & 37 & 15.3 \\
Government job & 26 & 12.3 \\
Agriculture & 21 & 8.7 \\
Housewife & 20 & 7 \\
Bricklayer & 7 & 6.7 \\
Tailor & & 2.3 \\
\hline Family type & 190 & \\
Nuclear & 78 & 63.3 \\
Joint & 32 & 10.7 \\
Extended & &
\end{tabular}

\begin{tabular}{lcc}
\hline Educational qualification & & \\
Illiterate & 12 & 4 \\
Nonformal education & 30 & 10 \\
Primary level & 26 & 8.7 \\
Lower secondary level & 23 & 7.7 \\
Secondary level & 34 & 11.3 \\
Higher secondary level & 53 & 17.7 \\
Bachelor level & 76 & 25.3 \\
Master's level or above & 46 & 15.3 \\
\hline Marital status & & \\
Married & 211 & 70.3 \\
Unmarried & 80 & 26.7 \\
Widowed & 9 & 3 \\
\hline
\end{tabular}

Family monthly income (NPR)

$\begin{array}{lcc}\leq 20,000 & 58 & 19.3 \\ 21,000-40,000 & 120 & 40 \\ 41,000-60,000 & 85 & 28.3\end{array}$

$\begin{array}{lrr}41,000-60,000 & 85 & 28.3 \\ >60,000 & 37 & 12.3\end{array}$

Mean income NPR 39523.33, SD \pm 17762.916, Min. NPR 10,000, and Max NRP 90,000

drinking, and alcohol beverages consumed. Most 85 (45.5\%) respondents responded that curiosity to test was a reason for intake of the first drink, and almost four-fifths 156 (83.4\%) respondents were habitual to an alcoholic drink. Majority of $152(81.3 \%)$ respondents have consumed beer followed by 124 (66.3\%) wine, 84 (44.9\%) spirits (vodka/rum/whisky), 60 (32.1\%) chang/jand, and rest 19 (10.2\%) respondent have consumed Aila respectively. 
TABLE 3: Distribution of respondents on the AUDIT-risk level and practice towards alcohol consumption $(n=300)$.

\begin{tabular}{lccc}
\hline AUDIT-risk level & AUDIT score & No. of respondents $(n)$ & Percentage (\%) \\
\hline Zone-I (low-risk drinking) & 0 to 7 & 131 & 51 \\
Zone-II (higher-risk drinking) & 8 to 15 & 83 & 17 \\
Zone-III (harmful and hazardous drinking) & 16 to 19 & 35 & 27.7 \\
Zone-IV (possible alcohol dependence) & 20 to 40 & & 11.7 \\
\hline Practice on alcohol consumption & & 131 & 43.7 \\
Nonproblematic drinkers & $0-7$ & 169 & 56.3 \\
Problematic drinkers & $7-40$ & & \\
\hline
\end{tabular}

Mean of AUDIT score $11.825, \mathrm{SD} \pm 8.831$.

TABLE 4: Distribution of respondents by reason for the first intake, continuation of drinking alcohol, and alcohol beverages consumed $(n=187)$.

\begin{tabular}{lcc}
\hline Reason for first intake & No. of respondents $(n)$ & Percentage $(\%)$ \\
\hline Curiosity to test & 85 & 45.5 \\
Peer pressure & 42 & 22.5 \\
To confirm to social norms & 55 & 29.4 \\
To relieve stress/pressure & 5 & 2.7 \\
\hline${ }^{*}$ Reasons for continuation & 156 \\
Now drinking alcohol is habitual & 132 \\
To celebrate happiness & 94 \\
To forget worries & 74 \\
To obey social norms and values & 63 \\
Peer pressure & 47 \\
To reduce workload & & 83.4 \\
${ }^{*}$ Alcohol beverages consumed & 152 \\
Beer & 124 \\
Wine & 84 \\
Spirits (Vodka/Rum/Whisky) & 60 \\
Chang/Jand & 19 \\
Aila & 50.3 \\
\hline
\end{tabular}

${ }^{*}$ Multiple responses.

3.3. Associations between Different Variables. Table 5 presents the multiple regression analysis of practice towards alcohol consumption with associated factors. A total of $56.3 \%$ of adults were problematic drinkers, and the rest $43.7 \%$ were nonproblematic drinkers. Results from bivariate analysis revealed age of respondents, gender, ethnicity, and occupation were having a significant association with alcohol drinking practices with $p$ value less than or equal to 0.05 , and these variables were further entered into the multivariable regression analysis model for confounding adjustment. However, variables such as family type, education status, marital status, and family monthly income were not found significant with alcohol practice. Results from the multivariable regression analysis model identified adults within the age group of 25-34 years and 35-44 years along with males significantly associated with problematic alcohol consumption. Adults within the age group 25-34 years and 35-44 years were 7.4 times $(\mathrm{AOR}=7.4, \mathrm{CI}$ : 1.97-27.60) and 5.7 times ( $\mathrm{AOR}=5.7, \mathrm{CI}: 1.58-20.56)$ more likely to be problematic drinkers than their counterparts who were from the age group of 55-64 years. Males were 6.9 times more likely to be problematic drinkers $(\mathrm{AOR}=6.9, \mathrm{CI}$ : 3.35-14.26) than females. After being subjected to the multivariable model, ethnicity and occupation of respondents were not found to be associated with problematic consumption, which was as seen significant in bivariate analysis.

\section{Discussion}

This study shows that about two-fifth (43.7\%) respondents fall under low-risk drinking (Zone I), 17\% higher-risk drinking (Zone II), 27.7\% harmful and hazardous drinking (Zone III), while rest $11.7 \%$ were under possible alcohol dependence (Zone IV) under the guidance of AUDIT-risk level category. This study contradicts with the study done by Davis et al. [18] which stated $32 \%$ respondent's low-risk drinkers and $26 \%$ respondents as high-risk drinkers. Another study done by Dunne et al. [19] stated $12.0 \%$ respondents had hazardous drinking, $0.9 \%$ harmful drinking, and $0.6 \%$ as probable alcohol dependence. These rates were found lowest than our study. Such discrepancy in the AUDIT zone might be connected with variation in practice towards alcohol drinking in different parts of the world and might be linked with a selection of study design and study method conducted. This present study revealed that most of the respondents $(45.5 \%)$ initiated alcohol drinking was owing to the curiosity of test followed by peer pressure $(22.5 \%)$. In addition, most of the respondents $(83.4 \%)$ became habitual to drinking, while $70.6 \%$ were drinking continuously to celebrate happiness. These findings were found dissimilar with the study done by Katyal et al. [20] who explored the most common reason for first intake being peer pressure (66.7\%) and curiosity to drink 


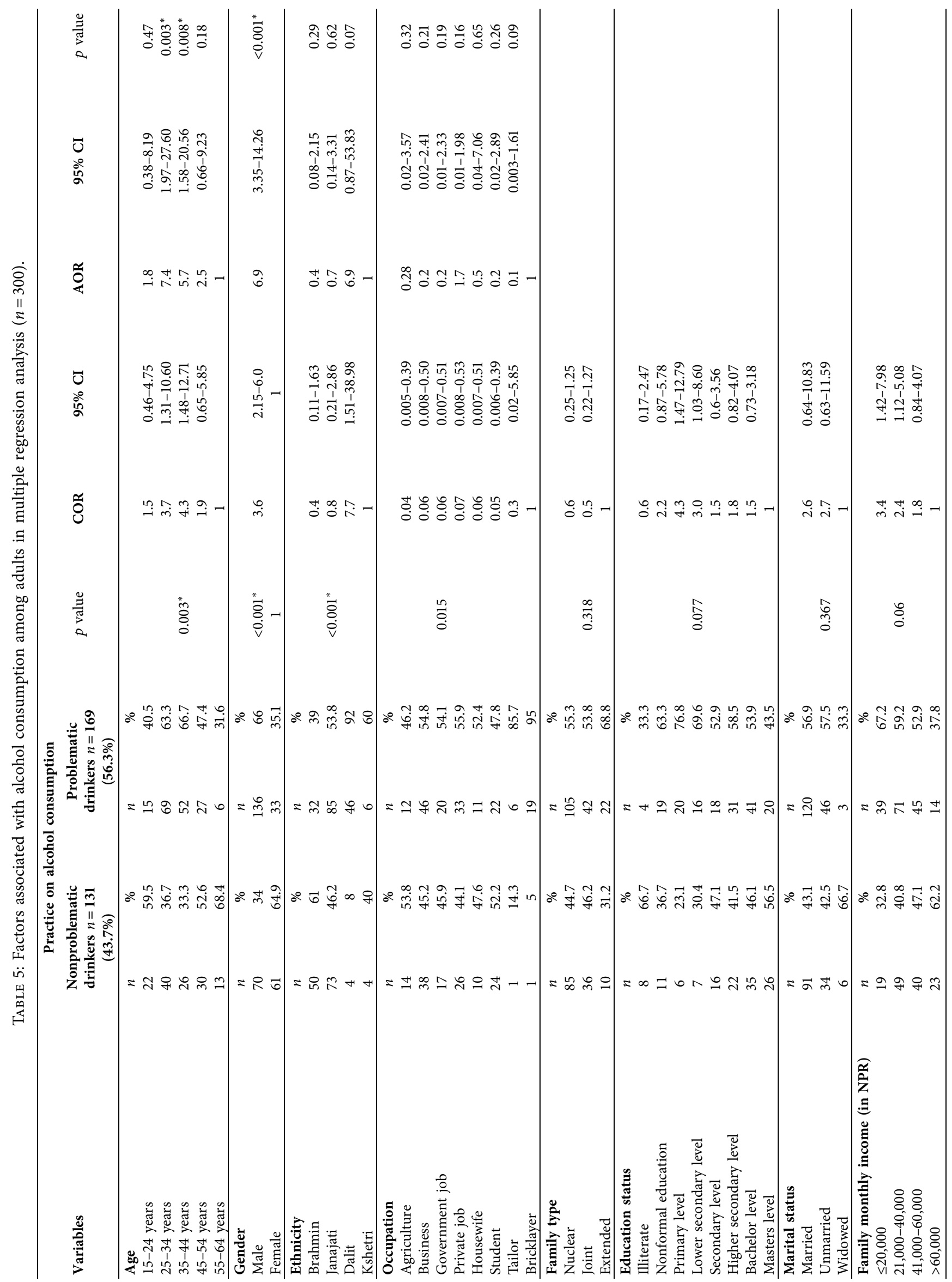


(2.1\%) and reasons for continuing alcohol drinking to be peer pressure $(38.5 \%)$ and to be sociable (32.3\%). Also, these present study findings were found inconsistent with other studies [21-26]. This discrepancy might be linked with various multiple factors which influence alcohol drinking in different study settings.

In this present study, respondents within the age group of 25-34 years and 35-44 years along with gender were having a significant association with problematic alcohol consumption $(p<0.05)$, and also males were found 6.9 times more likely to be problematic drinkers than females. This study is in line with study done by Ganesh Kumar et al. [27] who found adults within the age group 11-44 years and gender having a significant association with alcohol use $(p<0.05)$. However, males were found 11.23 times more likely to use alcohol in comparison with female. This study result is found inconsistent with the study done by Mekonen et al. [28] who stated sex was not having any association with problematic drinking while variables like having alcohol user intimate friend, ever use of substance, academic achievement, and probable social phobia having a significant association with problematic drinking $(p<0.001)$. This discrepancy might be due to difference in practice status among respondents in different study settings and methodology adopted. In this study, about four-fifth $(81.3 \%)$ respondents drank beer followed by twothirds $(66.3 \%)$ wine and spirits (44.9\%). This finding was found dissimilar to a study conducted by Tomkins et al. [29] in Izhevsk, Russia, which found 79\% respondents drank spirits and $8 \%$ drank surrogates occasionally in the past year, while $25 \%$ drank spirits and $4 \%$ drank surrogates at least weekly. This discrepancy might link with social and culture aspects of drinking. Moreover, this study result found similar with Esther and Jackson [30] and Pham et al. [31] who reported beer as the most common type of alcoholic beverage consumed. This study stated that two-fifth $(43.7 \%)$ of the respondents were nonproblematic drinkers, while $56.3 \%$ respondents were problematic drinkers. This study finding disagreed with the findings of cross-sectional study conducted by Chaudhary et al. [32] which revealed $12.7 \%$ problem drinkers and $87.3 \%$ participants were nonproblematic drinkers. The numbers of problematic drinkers were high in this study. The discrepancy in finding might be linked to the difference in the practice level of alcohol in multiple ethnic groups that exist in Nepal.

\section{Conclusion}

Problematic alcohol consumption among males was common and significantly associated within the age group of 25-34 years and 35-44 years. This study concerns the need for policy makers to lunch awareness programs and community-based interventional programs considering identified factors associated with excessive drinking.

\section{Abbreviations}

STEPS: STEPwise approach to NCD risk factor surveillance NDHS: Nepal demographic and health survey

NPR: Nepalese rupee
COR: Crude odds ratio

AOR: Adjusted odds ratio.

\section{Data Availability}

The data that support the findings of this study are openly available from the corresponding author upon request.

\section{Conflicts of Interest}

The authors declare that they have no conflicts of interest.

\section{Acknowledgments}

The authors would like to thank the entire respondents for active participation in this research. The authors are equally pleased to the Universal College of Medical Sciences and Teaching Hospital (UCMS-TH) and the District Health office (DHO) of Syangja district for granting approval for the research work.

\section{References}

[1] World Health Organization, Global Status Report on Alcohol and Health 2018, World Health Organization, Geneva, Switzerland, 2019.

[2] M. G. Griswold, N. Fullman, C. Hawley et al., "Alcohol use and burden for 195 countries and territories, 1990-2016: a systematic analysis for the global burden of disease study 2016," The Lancet, vol. 392, no. 10152, pp. 1015-1035, 2018.

[3] J. Manthey, K. D. Shield, M. Rylett, O. S. M. Hasan, C. Probst, and J. Rehm, "Global alcohol exposure between 1990 and 2017 and forecasts until 2030: a modelling study," The Lancet, vol. 393, no. 10190, pp. 2493-2502, 2019.

[4] R. Burton and N. Sheron, "No level of alcohol consumption improves health," The Lancet, vol. 392, no. 10152, pp. 987-988, 2018.

[5] B. Secretan, K. Straif, R. Baan et al., "A review of human carcinogens-part E: tobacco, areca nut, alcohol, coal smoke, and salted fish," The Lancet Oncology, vol. 10, no. 11, pp. 1033-1034, 2009.

[6] Ministry of Health, New ERA, and ICF, Nepal Demographic and Health Survey 2016, Ministry of Health, New ERA, and ICF, Kathmandu, Nepal, 2016, https://www.dhsprogram. com/pubs/pdf/fr336/fr336.pdf.

[7] K. K. Aryal, S. Mehata, S. Neupane et al., "The burden and determinants of non communicable diseases risk factors in Nepal: findings from a nationwide STEPS survey," PLoS One, vol. 10, no. 8, p. e0134834, 2015.

[8] N. Thapa, K. K. Aryal, R. Puri et al., "Alcohol consumption practices among married women of reproductive age in Nepal: a population based household survey," PLoS One, vol. 11, no. 4, p. e0152535, 2016.

[9] J. Collin and S. Casswell, "Alcohol and the sustainable development goals," The Lancet, vol. 387, no. 10038, pp. 2582-2583, 20165.

[10] R. Jenkins, C. Othieno, L. Ongeri et al., "Alcohol consumption and hazardous drinking in western Kenya-a household survey in a health and demographic surveillance site," $B M C$ Psychiatry, vol. 15, no. 1, pp. 1-0, 2015.

[11] D. Alemu, M. Soboka, E. Tesfaye, G. Ahmed, and Y. Tesfaye, "Alcohol use disorder and associated factors among Jimma 
University undergraduate students," Psychology Research and Behavior Management, vol. 13, pp. 609-618, 2020.

[12] "Nepal STEPS survey 2019 alcohol consumption and policy fact sheet," 2019, http://nhrc.gov.np/wp-content/uploads/ 2019/11/Alcohol-Factsheet.pdf.

[13] A. K. Bhandari, "Municipality declaration, urban imagination and urban experience A case of putalibazaar and walling, Syangja, Nepal," Himalayan Journal of Sociology and Anthropology, vol. 6, pp. 1-21, 2014.

[14] Syangja VDC Level Report, Central Bureau of Statistics, Kathmandu, Nepal, 2014, https://cbs.gov.np/.

[15] GoN National Planning Commission Central Bureau of Statistic, Statistical Pocket Book of Nepal 2018:1-416, Central Bureau of Statistics, Kathmandu, Nepal, 2019, https:// muannepal.org.np/municipality_profile/putalibazarmunicipality/.

[16] T. F. Babor, J. C. Higgins-Biddle, J. B. Saunders, and M. G. Monteiro, "The alcohol use disorders identification test," 2001, https://www.drugabuse.gov/sites/default/files/audit.pdf.

[17] UN Nepal, "Profile: Gandaki province," 2019, https://un.org. np/sites/default/files/doc_publication/2020-07/Province\% 204.pdf.

[18] A. K. Davis, M. A. Walton, K. M. Bohnert, C. Bourque, and M. A. Ilgen, "Factors associated with alcohol consumption among medical cannabis patients with chronic pain," Addictive Behaviors, vol. 77, pp. 166-171, 2018.

[19] J. Dunne, A. Kimergård, J. Brown et al., "Attempts to reduce alcohol intake and treatment needs among people with probable alcohol dependence in England: a general population survey," Addiction, vol. 113, no. 8, pp. 1430-1438, 2018.

[20] R. Katyal, R. Bansal, K. Goel, and S. Sharma, "Hazardous, harmful and dependent alcohol users according to audit in an Urban Slum, Meerut," International Journal of Medical Science and Public Health, vol. 2, no. 1, pp. 26-31, 2013.

[21] R. Ghulam, I. Rahman, S. Naqvi, and S. R. Gupta, “An epidemiological study of drug abuse in urban population of Madhya Pradesh," Indian Journal of Psychiatry, vol. 38, no. 3, pp. 160-5, 1996.

[22] J. Singh, G. Singh, V. Mohan, and A. S. Padda, “A comparative study of prevalence of regular alcohol users among the male individuals in an urban and rural area of distt," Amritsar, Punjab. Indian Journal of Community Medicine, vol. 25, no. 2, p. 73, 2000.

[23] P. K. Meena, P. Khanna, A. K. Vohra, and R. Rajput, "Prevalence and pattern of alcohol and substance abuse in urban areas of Rohtak city," Indian Journal of Psychiatry, vol. 44, no. 4, pp. 348-52, 2002.

[24] K. S. Neogi, S. D. Kandpal, and C. M. Rawat, "Prevalence of alcoholism among the males in a rural and urban area of district Dehradun (Uttaranchal)," Indian Journal of Preventive and Social Medicine, vol. 34, no. 3, p. 4, 2003.

[25] V. Khosla, K. R. Thankappan, G. K. Mini, and P. S. Sarma, "Prevalence \& predictors of alcohol use among college students in Ludhiana, Punjab, India," Indian Journal of Medical Research, vol. 128, no. 1, pp. 79-81, 2008.

[26] N. Girish, R. Kavita, G. Gururaj, and V. Benegal, "Alcohol use and implications for public health: patterns of use in four communities," Indian Journal of Community Medicine: Official Publication of Indian Association of Preventive \& Social Medicine, vol. 35, no. 2, pp. 238-44, 2010.

[27] S. Ganesh Kumar, K. C. Premarajan, L. Subitha, E. Suguna, and V. K. Vinayagamoorthy, "Prevalence and pattern of alcohol consumption using alcohol use disorders identification test (AUDIT) in rural Tamil Nadu, India," Journal of Clinical and Diagnostic Research: Journal of Clinical and Diagnostic Research, vol. 7, no. 8, p. 1637, 2013.

[28] T. Mekonen, W. Fekadu, T. Chane, and S. Bitew, "Problematic alcohol use among university students," Frontiers in Psychiatry, vol. 8, p. 86, 2017.

[29] S. Tomkins, L. Saburova, N. Kiryanov et al., "Prevalence and socio-economic distribution of hazardous patterns of alcohol drinking: study of alcohol consumption in men aged 25-54 years in Izhevsk, Russia," Addiction, vol. 102, no. 4, pp. 544-553, 2007.

[30] U. Esther and N. Jackson, Cheap Drinks: An Exploratory Audit of Alcohol Prices at Off-Licences across Támaki Makaurau/ Auckland, Alcohol Healthwatch, Auckland, New Zealand, 2021.

[31] D. B. Pham, A. R. Clough, H. V. Nguyen, G. B. Kim, and P. G. Buettner, "Alcohol consumption and alcohol-related problems among Vietnamese medical students," Drug and Alcohol Review, vol. 29, no. 2, pp. 219-226, 2010.

[32] V. Chaudhary, R. Katyal, S. P. Singh, H. S. Joshi, D. Upadhyay, and A. Singh, "A study on pattern of alcohol use using AUDIT among the college students in a medical college of North India," National Journal of Community Medicine, vol. 6, pp. 253-257, 2015. 